\title{
Distribuição espacial da concentração de nutrientes em sedimentos na Laguna hipersalina de Araruama - RJ, Brasil
}

Kaylanne Montenegro da Silva ${ }^{1 *}$ Teresa Cristina S. M. Guimarães ${ }^{2}$ Julio Cesar F A. Wasserman ${ }^{3}$

${ }^{1}$ Departamento de Saúde e Saneamento Ambiental

Escola Nacional de Saúde Pública Rio de Janeiro/RJ - Brasil.

${ }^{2}$ Departamento de Geoquímica Instituto de Química Universidade Federal Fluminense Niterói/RJ - Brasil.

${ }^{3}$ Departamento de Análise Ambiental Instituto de Geociências Universidade Federal Fluminense Niterói/RJ - Brasil.

* Autor correspondente kaylannemontenegro@gmail.com

\section{RESUMO}

O presente estudo foi realizado na Laguna de Araruama, Rio de Janeiro. A poluição na laguna tem prejudicado a estrutura do ecossistema e causado a intensificação do processo de eutrofização. Para melhorar a qualidade da água, é proposta a abertura de canais da laguna com o mar, porém pode resultar na remobilização dos nutrientes no sedimento para a coluna d'água. Considerando a importância do sedimento como compartimento de estocagem de nutrientes, o objetivo deste estudo foi determinar as concentrações de nutrientes nos sedimentos e na água intersticial e sua distribuição nos sedimentos. Foram realizadas medições de $\mathrm{pH}$ e Eh no sedimento, condutividade e temperatura ao longo da coluna d'água. Foi realizada a granulometria e determinadas as concentrações de amônio, nitrito, nitrato e fosfato na água intersticial, e as concentrações totais de fósforo, nitrogênio e carbono nos sedimentos. Diante dos resultados granulométricos, a maior parte da laguna encontra-se com formações arenosas. $\mathrm{O}$ sedimento apresentou temperaturas entre $22^{\circ} \mathrm{C}$ e $25^{\circ} \mathrm{C}, \mathrm{pH}$ básico $(7,1-8,2)$ e características redutoras $(-400 \mathrm{mV})$. Nas estações próximas a São Pedro da Aldeia e Araruama, há teores, considerados altos, de nitrogênio total no sedimento devido ao alto aporte de esgotos lançado nos rios que deságuam na laguna. Altas concentrações de fósforo total também foram encontradas na região do Canal de Itajuru, mais próxima do mar, que por ter menor salinidade, possui maior produtividade primária. Conclui-se que a laguna apresenta um grau elevado de poluição por nutrientes, em pontos específicos, devido a aportes oriundos do lançamento de esgotos.

Palavras-Chave: Fósforo, Nitrogênio, Interface água-sedimento, Araruama, Geoquímica.

\section{ABSTRACT}

The present study was carried out in Laguna de Araruama, Rio de Janeiro. Pollution in the lagoon has hampered the ecosystem structure and caused the eutrophication process to intensify. In order to improve water quality, it is proposed to open channels of the lagoon with the sea, but may result in the remobilization of the nutrients in the sediment to the water column. Considering the importance of sediment as a nutrient storage compartment, the objective of this study was to determine nutrient concentrations in sediments and interstitial water and their distribution in the sediments. Measurements of $\mathrm{pH}$ and $\mathrm{Eh}$ were made in the sediment, conductivity and temperature along the water column. The granulometry was determined and the concentrations of ammonium, nitrite, nitrate and phosphate in the interstitial water were determined, and the total concentrations of phosphorus, nitrogen and carbon in the sediments. Considering the granulometric results, most of the lagoon has sandy formations. The sediment presented temperatures between $22{ }^{\circ} \mathrm{C}$ and $25^{\circ} \mathrm{C}$, basic $\mathrm{pH}(7.1$ - 8.2) and reducing characteristics $(-400 \mathrm{mV})$. In the stations near São Pedro da Aldeia and Araruama, there are high levels of total nitrogen in the sediment due to the high amount of sewage discharged into the rivers that flow into the lagoon. High concentrations of total phosphorus were also found in the region of the 
Itajuru Channel, closer to the sea, which due to its lower salinity has higher primary productivity. It is concluded that the lagoon presents a high degree of pollution by nutrients, in specific points, due to the contributions caused by the discharge of sewage.

Keywords: Phosphorus, Nitrogen, Water-sediment interface, Araruama, Geochemistry.

\section{INTRODUÇÃO}

A disponibilidade de água e nutrientes é fundamental para o crescimento biológico em um ecossistema. Os nutrientes são essenciais para a manutenção da vida nos ecossistemas aquáticos, pois são os "blocos" de construção químicos básicos das células vivas. Os elementos químicos necessários para as células biológicas variam de macronutrientes, que são aqueles que são requeridos em maior quantidade (por exemplo, carbono, oxigênio, hidrogênio, nitrogênio, fósforo, potássio, magnésio, sódio, cálcio, entre outros), e micronutrientes, que são aqueles que são requeridos em menor quantidade (por exemplo, ferro, manganês, cobre, zinco, molibdênio, entre outros) (Gerritse, 2000).

No entanto, apenas alguns são necessários em quantidades relativamente grandes, como o nitrogênio e o fósforo, que são os mais importantes para plantas e algas. Além disso, esses elementos são ambientalmente os nutrientes mais críticos e limitantes no ecossistema aquático. A biomassa total aumenta linearmente com a quantidade de nitrogênio ou fósforo disponíveis, se nenhum outro fator for limitante (Oliveira, 2010).

A entrada de nutrientes de fonte terrestre em corpos de água superficiais é um fenômeno natural, porém, o aumento da população humana e a expansão das áreas urbanizadas sem planejamento urbanístico promove um incremento nas cargas de lançamento de lixo e esgoto, acelerando o processo de eutrofização natural desses ambientes. Altos níveis de eutrofização em lagunas costeiras devido à atividade antrópica têm sido documentados em vários países do mundo, provocando impactos que podem levar a floração de algas tóxicas, hipoxia, anoxia, mortalidade de peixes, redução da biodiversidade e perda do estoque pesqueiro, causando diversos prejuízos à população que vive nas cidades às margens desses ecossistemas (Silva et al., 2017).

A área de estudo deste trabalho é a Laguna de Araruama, localizada na Região dos Lagos, no estado do Rio de Janeiro. A laguna possui uma grande beleza cênica e uma rica biodiversidade. Assim, a região possui um grande potencial de exploração econômica, principalmente através do turismo e da pesca. Entretanto, esta região vem sofrendo uma intensa degradação ambiental, devido à ocupação desordenada na região, principalmente nos períodos de alta temporada, que resulta no aumento do lançamento de lixo e esgotos nos corpos d'água, causando sua contaminação (Kjerfve \& Knoppers, 1999; Knoppers \& Bidone, 1999). O lançamento de esgotos não tratados na laguna intensifica $o$ processo de eutrofização, que provoca sérios efeitos na estrutura do ecossistema, gerando desequilíbrios e podendo causar florações algais tóxicas. Estas, por sua vez, se acumulam nos organismos e podem levar a sua morte ou, caso estes sejam consumidos, podem causar danos à saúde humana. Portanto, este processo prejudica tanto a saúde ambiental da laguna, quanto a saúde da comunidade local (Wasserman et al., 2000).

Dentre as soluções propaladas com o intuito de melhorar a qualidade da água, a que retorna sistematicamente à mídia e que surge de estudos acadêmicos, é a abertura de canais ligando o sistema com o mar (Gava, 2008). Nestes estudos, e na percepção da população em geral, a solução é muito simples, basta abrir conexões com o mar, aumentando a taxa de renovação de água e, automaticamente, há uma melhora da qualidade do ambiente. Não obstante, uma análise mais aprofundada do problema mostra que existem algumas restrições teóricas a estes mecanismos. Um dos mecanismos que pode provocar resultados inesperados aos procedimentos de abertura de barras é o aumento da taxa de difusão de nutrientes do sedimento para a coluna d'água. Este mecanismo foi estudado por alguns autores (Zoumis \& Schmidt, 2001; Lopez, 2003) que observam um incremento na difusão devido às elevadas concentrações de nutrientes no sedimento e que, em contato com águas menos concentradas, geram um forte gradiente. Evidentemente, este gradiente vai se atenuando com o tempo à medida que os nutrientes do sedimento são eliminados para a coluna d'água e esta vai se depurando pela maior taxa de renovação. A grande questão 
ainda desconhecida é saber em quanto tempo estes nutrientes se esgotam.

Considerando a importância do sedimento como compartimento de estocagem de nutrientes, o presente estudo realizou a avaliação das concentrações de nutrientes no

\section{MATERIAIS E MÉTODOS}

\section{1. ÁREA DE ESTUDO}

A Lagoa de Araruama é localizada na Região dos Lagos, no estado do Rio de Janeiro (Figura 1), localizada entre as latitudes de sedimento e na água intersticial e sua distribuição nos sedimentos. Esse estudo poderá trazer a resposta para algumas das questões que afetam a qualidade ambiental e fazer com que a laguna volte a exercer sua função ecológica e turística $22^{\circ} 49^{\prime}$ e $22^{\circ} 57^{\prime} \mathrm{S}$ e longitudes $042^{\circ} 00^{\prime}$ e 042 $30^{\circ} \mathrm{W}$ (Bidegain \& Bizerril, 2002).
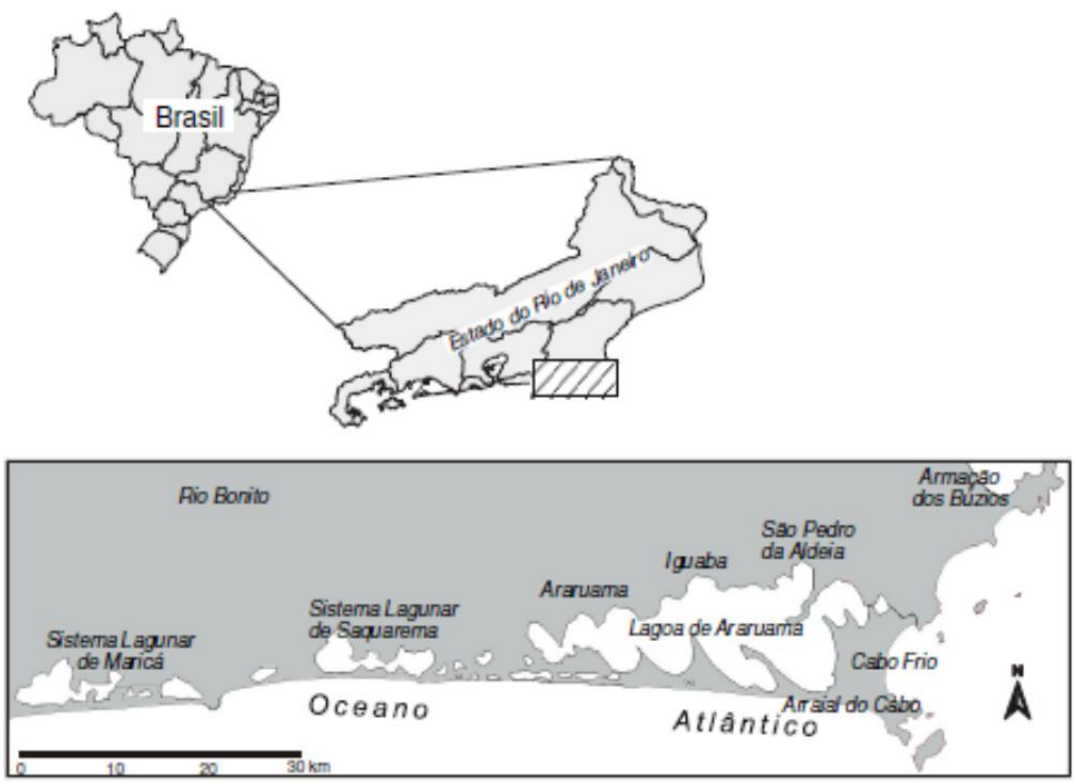

Figura 1

Localização da área de estudo e posição dos municípios do entorno.

Estende-se pelos municípios de Saquarema, Araruama, Iguaba Grande, São Pedro da Aldeia, Cabo Frio e Arraial do Cabo. Este ecossistema é classificado como uma laguna, pois é conectada ao Oceano Atlântico através de um canal permanente, chamado Canal de Itajuru, cuja largura varia entre 60 e $350 \mathrm{~m}$, localizado no município de Cabo Frio (Figura 2).

Após a coleta, foram realizadas medidas in situ dos parâmetros físico-químicos do sedimento com auxílio do medidor portátil de pH e potencial de oxi-redução (Eh), bem como do aparelho CTD (conductivity, temperature and depth) para mensurar temperatura $\mathrm{e}$ condutividade na coluna d'água. Uma alíquota das amostras foi centrifugada para a separação da água intersticial, na qual foram determinadas as concentrações de nutrientes dissolvidos. As amostras de água e sedimento foram colocadas em recipientes estanque, e transportadas para o laboratório em caixas térmicas a $4^{\circ} \mathrm{C}$. Todas as análises foram realizadas no laboratório de análise de águas do grupo Rede UFF de Meio Ambiente e Desenvolvimento Sustentável - REMADS, no Instituto de Geociências da UFF.

No laboratório, as amostras de água intersticial foram analisadas para a determinação das concentrações dos nutrientes dissolvidos: Amônio $\left(\mathrm{NH}_{4}{ }^{+}\right)$, Nitrito $\left(\mathrm{NO}_{2}{ }^{-}\right)$, Nitrato $\left(\mathrm{NO}_{3}{ }^{-}\right)$e Fosfato $\left(\mathrm{PO}_{4}{ }^{3-}\right)$. Os nutrientes Amônio, Nitrito e Fosfato foram quantificados com o procedimento colorimétrico, baseado na leitura da absorbância dos extratos obtidos no equipamento espectrofotômetro descrito por Grasshoff et al. (1983). A determinação de Nitrato foi realizada de acordo com o método simplificado do reagente resorcinol (Zhang \& Fisher, 2005), visto ser mais simples que o médoto de Grasshoff et al. (1983) e adequado para ambientes marinhos. 


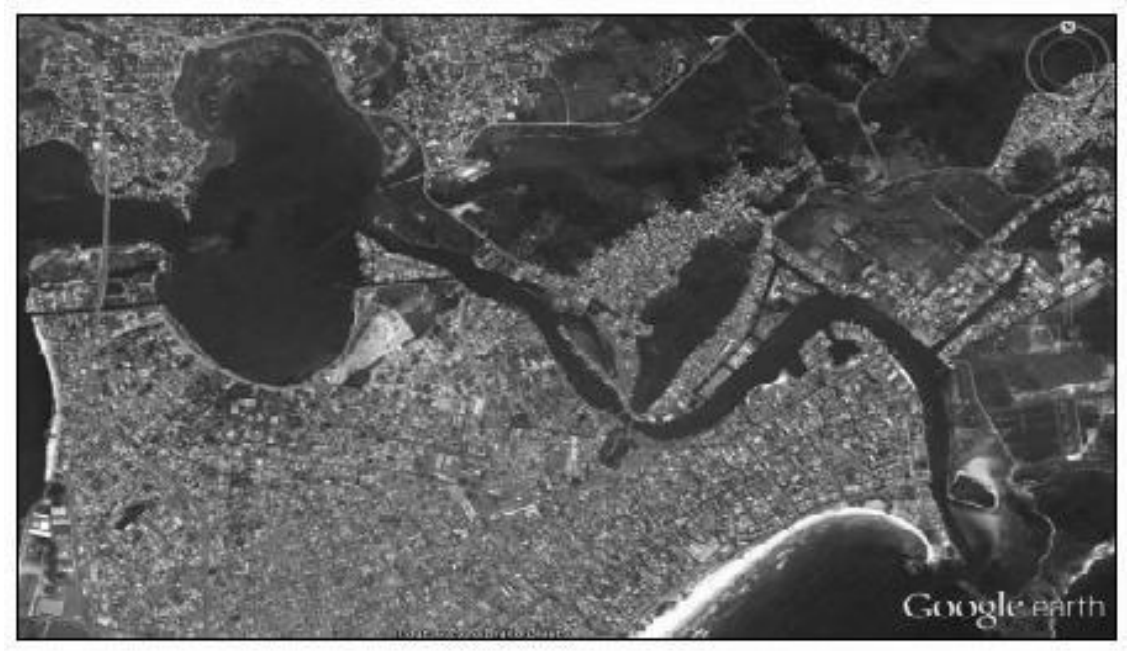

Figura 2

Foto de Satélite do Canal de Itajuru (Fonte: Google Earth, 2015).

Além desse canal, dois principais rios permanentes contribuem para a formação da laguna: o Rio das Moças e o Rio Mataruna, ambos localizados em Araruama, além de outros quatro rios que também deságuam na laguna.

A laguna ocupa uma área de $220 \mathrm{~km}^{2}$, com profundidade média de $3 \mathrm{~m}$, atingindo, no máximo, $17 \mathrm{~m}$. Possui $40 \mathrm{~km}$ de extensão, largura máxima de $13 \mathrm{~km}$, perímetro de 190 $\mathrm{km}$ e volume de 618 milhões de $\mathrm{m}^{3}$ (Kjerfve et al., 1996). Ao longo de sua extensão (LesteOeste), existem várias enseadas, recortadas por pontais de areia. Uma de suas principais características é a alta salinidade, em torno de 50 na parte central. Ela é considerada uma laguna hipersalina devido ao clima da região ser semiárido, gerando, assim, um balanço hídrico negativo e à renovação de suas águas ser pouco expressiva. Estas características tornam este ambiente um acumulador de elementos por natureza (Kjerfve \& Knoppers, 1999).

Na década de 70 , com a construção da
Ponte Rio-Niterói, houve um crescimento popula-cional desordenado nos municípios ao redor da laguna, principalmente em épocas de alta temporada, pois a população praticamente triplica de tamanho. $\mathrm{O}$ esgotamento sanitário sem planejamento adequado da região não acompanhou esse crescimento populacional. Atualmente, os rios que deságuam na Laguna de Araruama são repletos de esgotos que não são devidamente tratados. Isso torna suas águas escuras em determinados pontos e com cheiro forte, o que prejudica a população local. O grande problema das estações de tratamento de esgoto é que não são eliminados, dos esgotos tratados, os nutrientes como nitratos, fosfatos e minerais. Isso acaba hipernutrindo o sistema lagunar, que cria uma condição de eutrofização, gerando proliferações exageradas de algas. Assim, o oxigênio é consumido mais que o normal e proporciona a morte de peixes e de outros organismos, causando desequilíbrios ambientais na laguna e grandes problemas sociais e econômicos para população da região (Wasserman, 2006).

\subsection{AMOSTRAGEM E PROCEDIMENTOS ANALÍTICOS}

Em agosto de 2014, foram coletadas trinta e seis amostras de sedimento superficial, com auxílio de busca-fundo do tipo Van-veen, nos pontos demarcados da Laguna de Araruama (Figura 3).

Para determinação da concentração total de fósforo no sedimento, foi feita a oxidação das amostras e utilizada uma panela de pressão comum para a extração. Para este procedimento, uma alíquota de aproximadamente $15 \mathrm{mg}$ de amostra foi colocada em um frasco de vidro, juntamente com $10 \mathrm{~mL}$ de água destilada e $1,4 \mathrm{~mL}$ da solução oxidante. $\mathrm{O}$ frasco foi hermeticamente fechado e colocado na panela de pressão, contendo dois centímetros de água, e permaneceu em fogo brando.

Quando a pressão iniciou o calor foi mantido por trinta minutos. Da amostra oxidada dos frascos, foram separados $5 \mathrm{~mL}$ e em seguida, utilizaram-se os mesmos procedimentos para a determinação de fosfato, segundo método descrito por Grasshoff et al. (1983). 


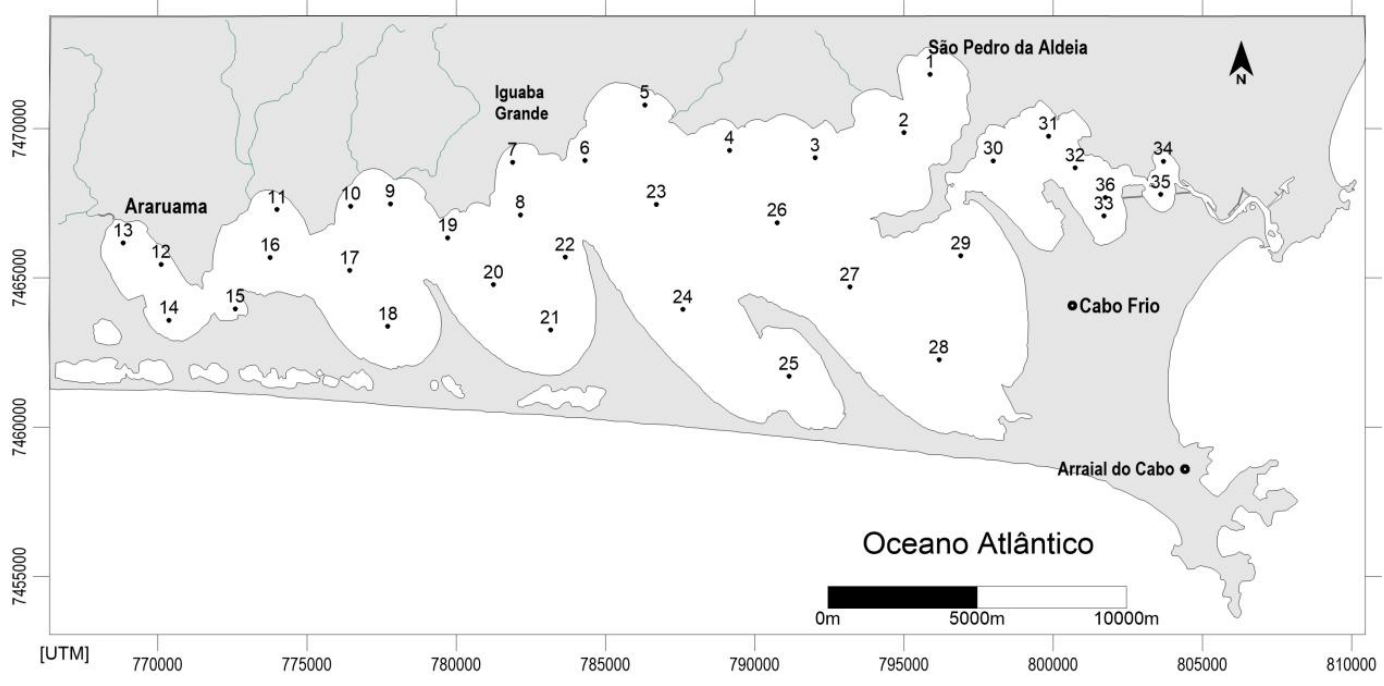

Para a quantificação de nitrogênio total e carbono orgânico total, as amostras foram secas em estufa, maceradas e submetidas a uma combustão a $950{ }^{\circ} \mathrm{C}$ sob atmosfera pura de oxigênio e os produtos foram transportados para um detector infravermelho que mede as concentrações de dióxido de carbono e óxidos de nitrogênio. Este procedimento foi realizado na EMBRAPA-Solos, Jardim Botânico (RJ, Brasil).

A análise granulométrica de finos foi realizada, inicialmente, em amostras úmidas, retirando-se a matéria orgânica por adição de peróxido de hidrogênio $\left(\mathrm{H}_{2} \mathrm{O}_{2}\right)$. Em seguida,

\section{RESULTADOS E DISCUSSÃO}

Os resultados das distribuições de parâmetros físico-químicos e concentrações de nutrientes no sedimento e na água intersticial estão apresentados nas figuras 4 a 12. Apesar da elevada salinidade da água (devido à grande quantidade de eletrólitos em solução), que deve atribuir poder tamponante elevado, o $\mathrm{pH}$ apresentou uma variação oscilando entre 7 e 8 (Figura 4).

Os valores mais baixos parecem associados às fontes de contaminação antrópica em toda a costa norte da laguna e no seu fundo oeste. Há uma correlação inversa entre o $\mathrm{pH}$ e a concentração de carbono total no sedimento $(\mathrm{p}<0,01)$, o que poderia justificar os baixos valores de $\mathrm{pH}$ nos
Estações de coleta das amostras na Laguna

foi adicionada uma solução de hexametafosfato de sódio $\left(\mathrm{Na}_{16} \mathrm{P}_{14} \mathrm{O}_{43}-40 \mathrm{~g} . \mathrm{L}^{-1}\right)$ para dispersar as partículas. A análise foi feita no granulômetro a laser MASTERSIZER 2000, da Malvern Instrument. Para a análise granulométrica de areia e cascalho, foi realizado o mesmo procedimento para retirada de matéria orgânica e secagem total das amostras em estufa. A leitura foi feita no granulômetro a laser CAMSIZER P4. Os parâmetros estatísticos foram calculados através do software GRADSTAT desenvolvido por Blott and Pye (2001), que tem como base de operação o Microsoft Excel, para Windows.

lugares onde há mais importantes aportes de carbono orgânico.

Por outro lado, o Eh (Figura 5) não apresenta uma boa correlação com o pH $(\mathrm{p}<0,01)$, mostrando que há outros fatores de controlam o potencial redox. Da mesma forma, a correlação entre o potencial redox e a concentração de carbono orgânico não é significativa, reforçando a distinção deste processo.

Existe uma forte dominância de amônio sobre as outras formas dissolvidas de nitrogênio na água intersticial (Figuras 6, 7 e 8), corroborando o caráter redutor da água intersticial em todo o sistema. 


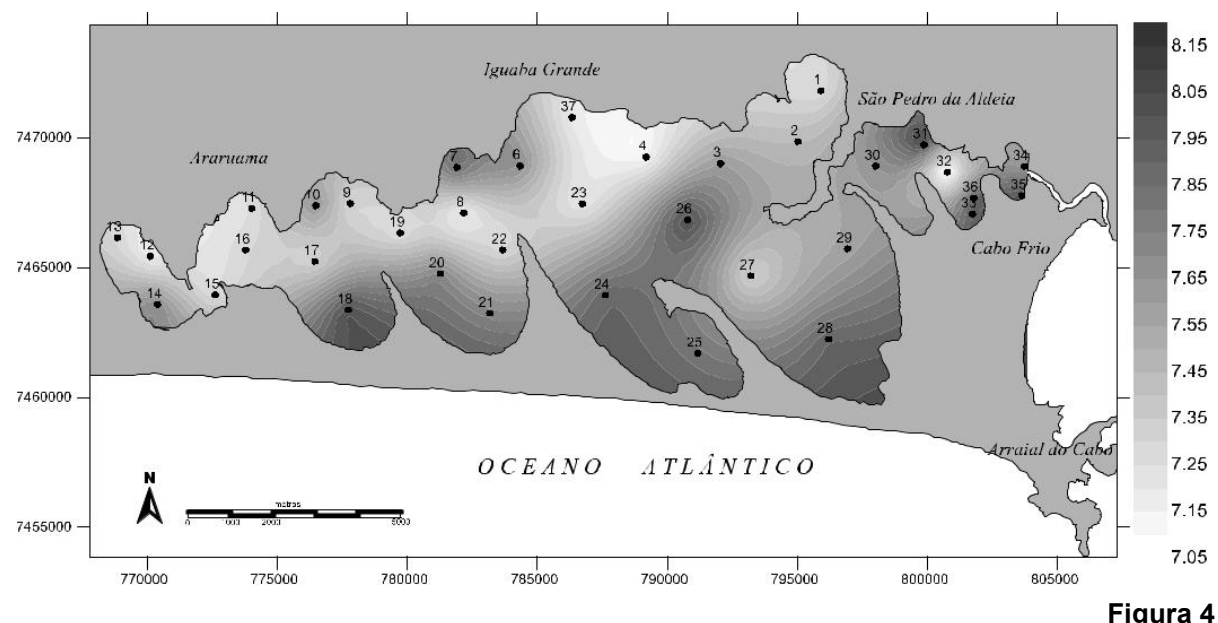

Distribuição do pH na água intersticial dos sedimentos da Laguna de Araruama.

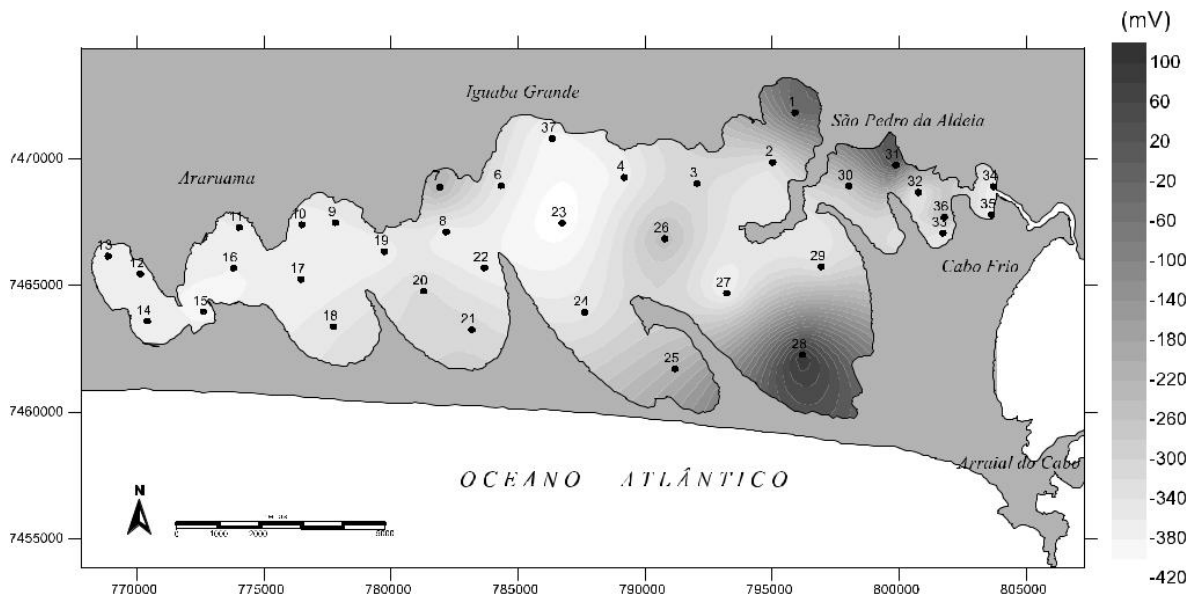

Figura 5

Distribuição do potencial redox (Eh) na água intersticial dos sedimentos da Laguna de Araruama.

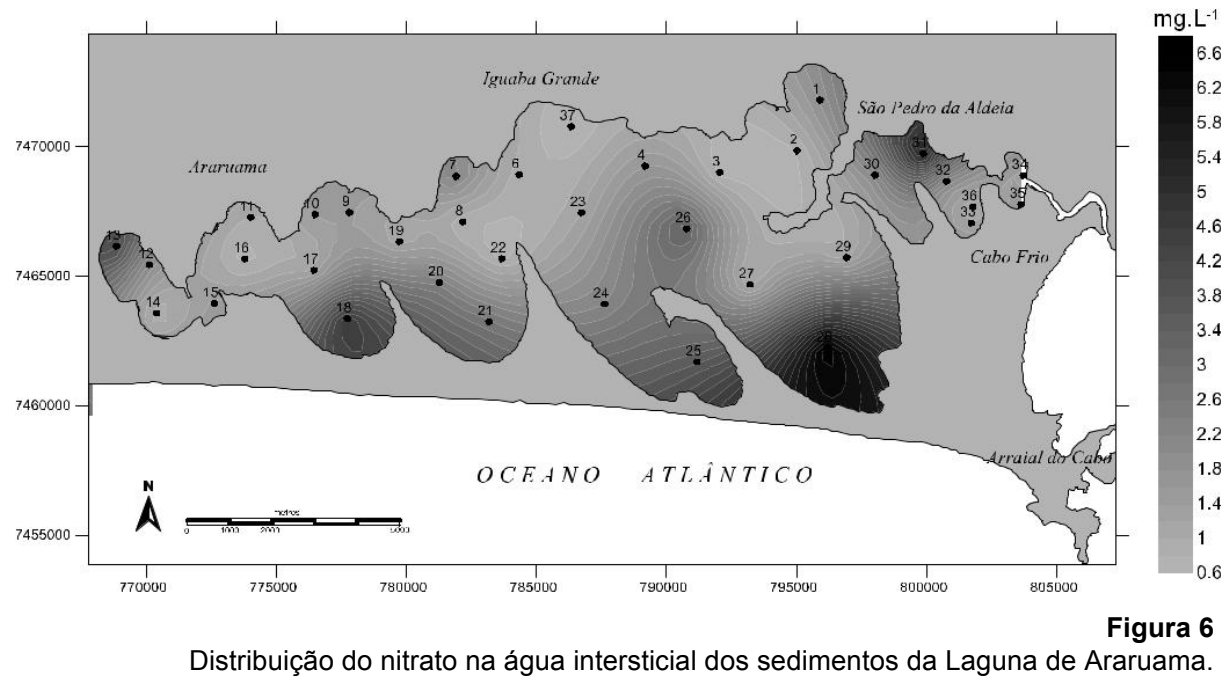




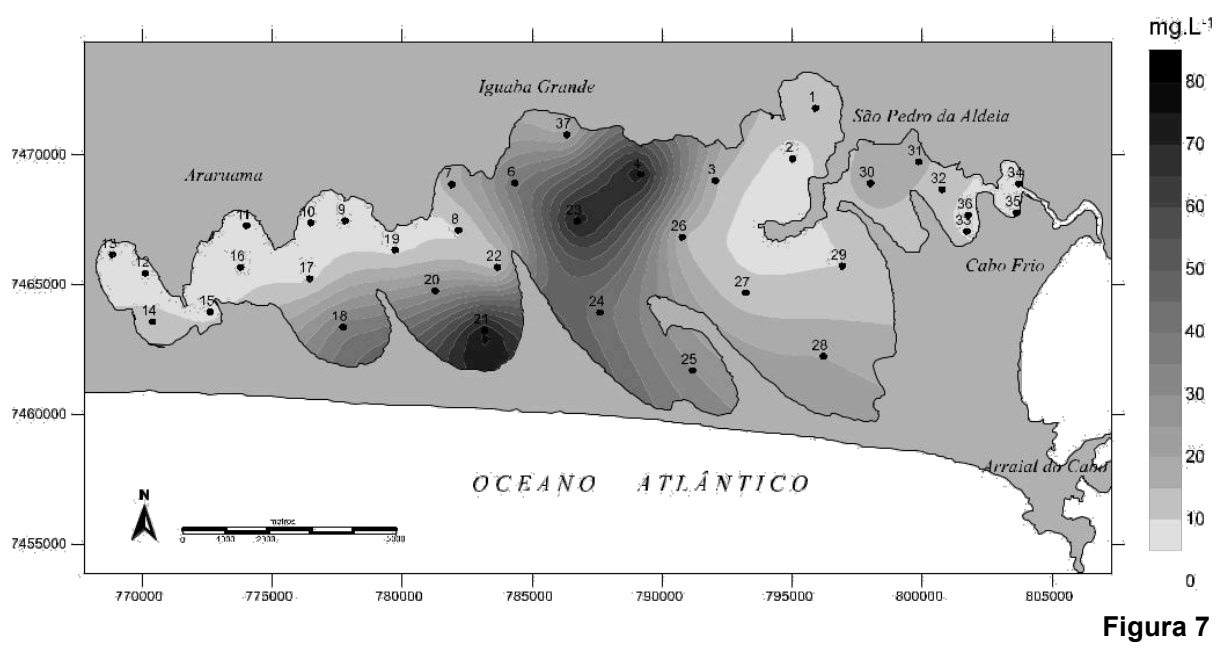

Distribuição do nitrito na água intersticial dos sedimentos da Laguna de Araruama.

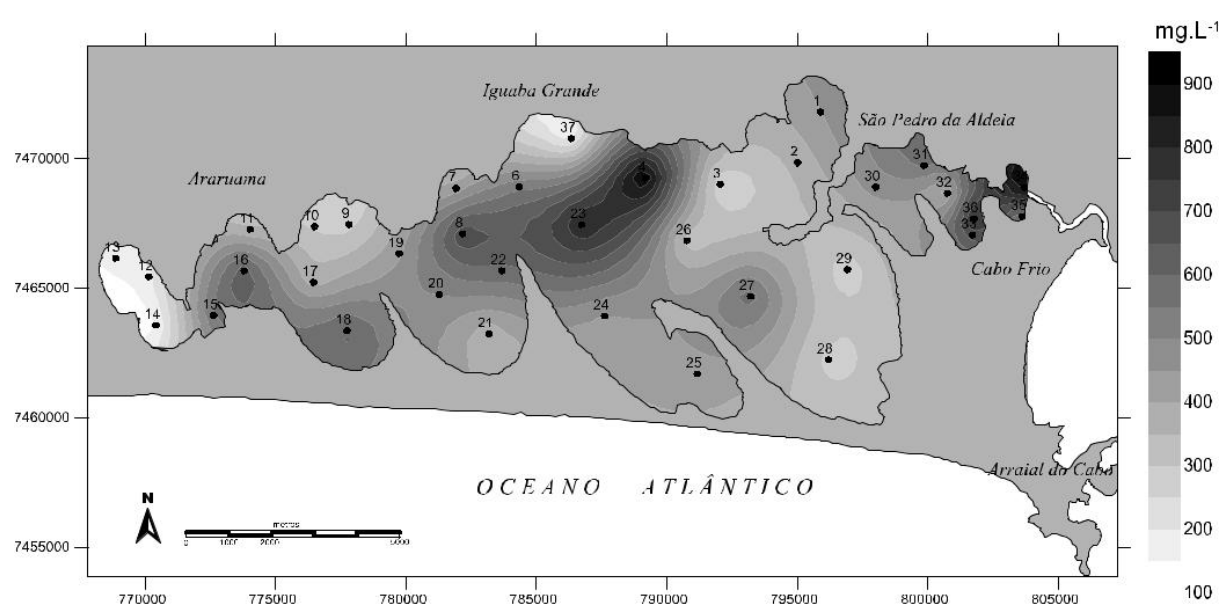

Figura 8

Distribuição do amônio na água intersticial dos sedimentos da Laguna de Araruama.

Mesmo nas regiões mais a leste, onde o potencial redox é um pouco mais oxidante, observa-se o domínio da forma amônio. Em termos de distribuição, observa-se uma forte concentração no meio da laguna, provavelmente associada a aportes oriundos do município de Iguaba Grande. Observa-se, também, um forte enriquecimento na região do Canal de Itajuru (Estações 34 e 35), que deve ser afetada pelos aportes do município de Cabo Frio.

De uma maneira geral, observa-se um certo padrão de espalhamento das concentrações de amônio em direção ao centro da laguna a partir da estação 4 (ao largo de Iguaba Grande), que está associado aos processos dinâmicos sedimentares. De fato, alguns autores (Alves, 2003; Alves et al., 2005) observam que a dinâmica sedimentar é muito intensa na laguna e alguns processos devem espalhar os sedimentos costeiros do norte, em direção às áreas mais profundas. Este espalhamento é materializado na forma de processos erosivos que anualmente reduzem as praias dos municípios de Iguaba Grande e Araruama, levando à necessidade de frequentes engordamentos de praia. Este processo parece promover, também, o transporte de nitrogênio total (Figura 9), levando o material até as estações 8 e 22 .

O processo de transporte não ocorre com o amônio, que rapidamente se dissolveria na água, mas na forma de nitrogênio total (que é mais refratário). Após a sedimentação, o nitrogênio total deve fornecer amônio para a água intersticial.

Tanto o fosfato dissolvido quanto o fósforo total (Figuras 10 e 11) encontram-se concentrados na porção Leste da laguna, nas proximidades do Canal de Itajuru. 


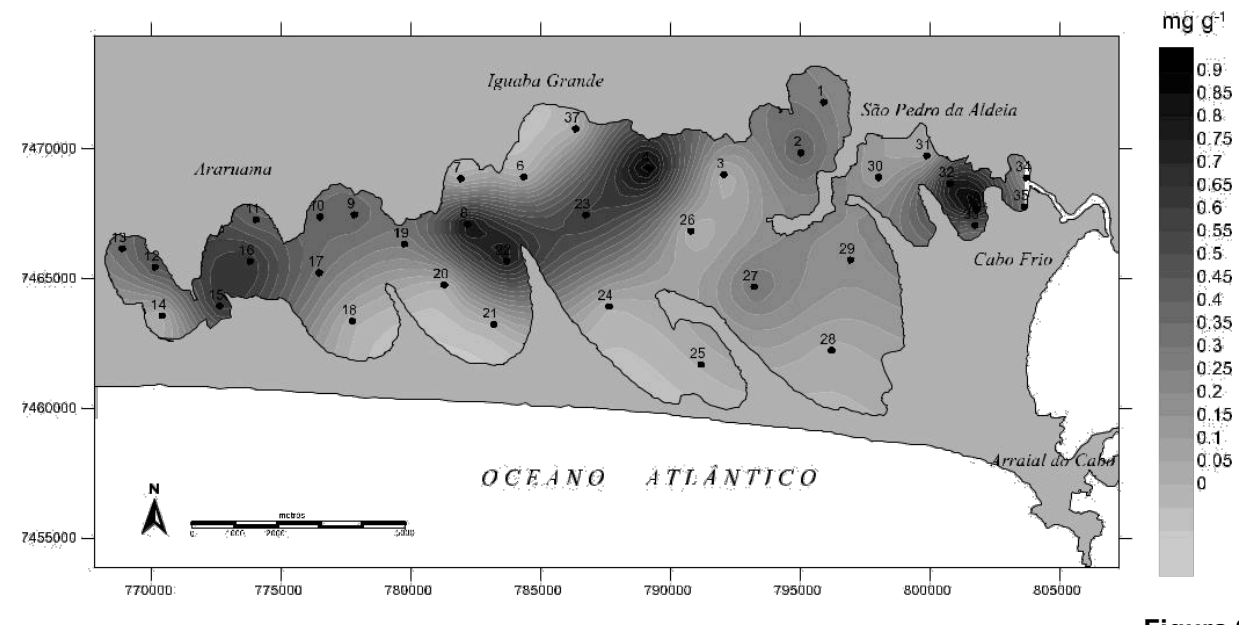

Figura 9

Distribuição do nitrogênio total nos sedimentos da Laguna de Araruama.

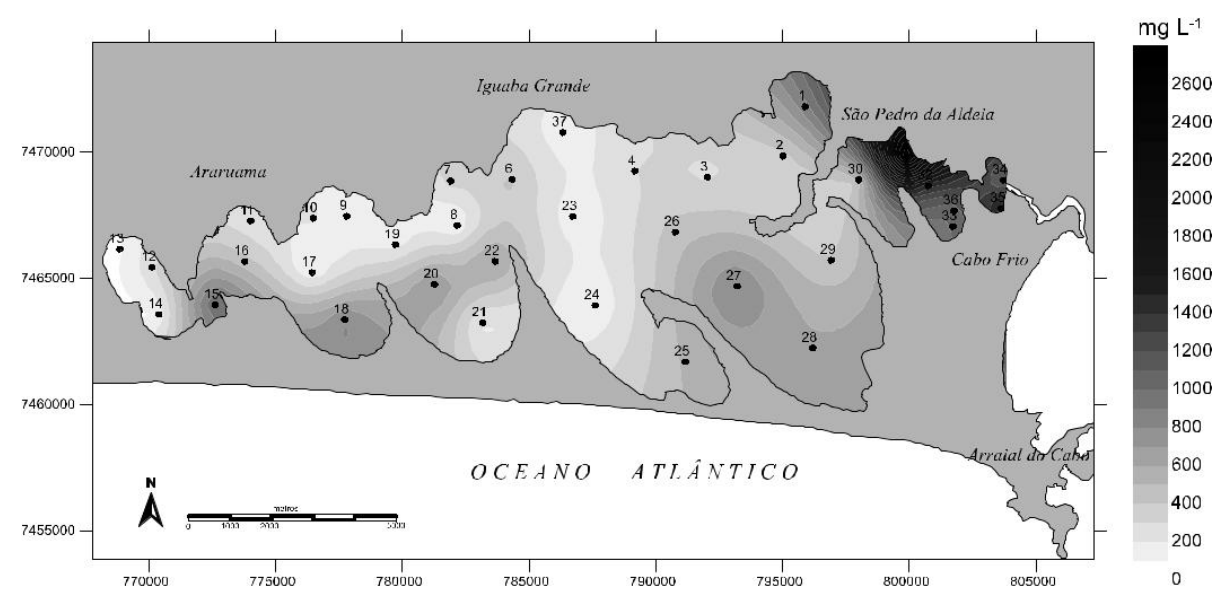

Figura 10

Distribuição do fosfato dissolvido na água intersticial dos sedimentos da Laguna de Araruama.

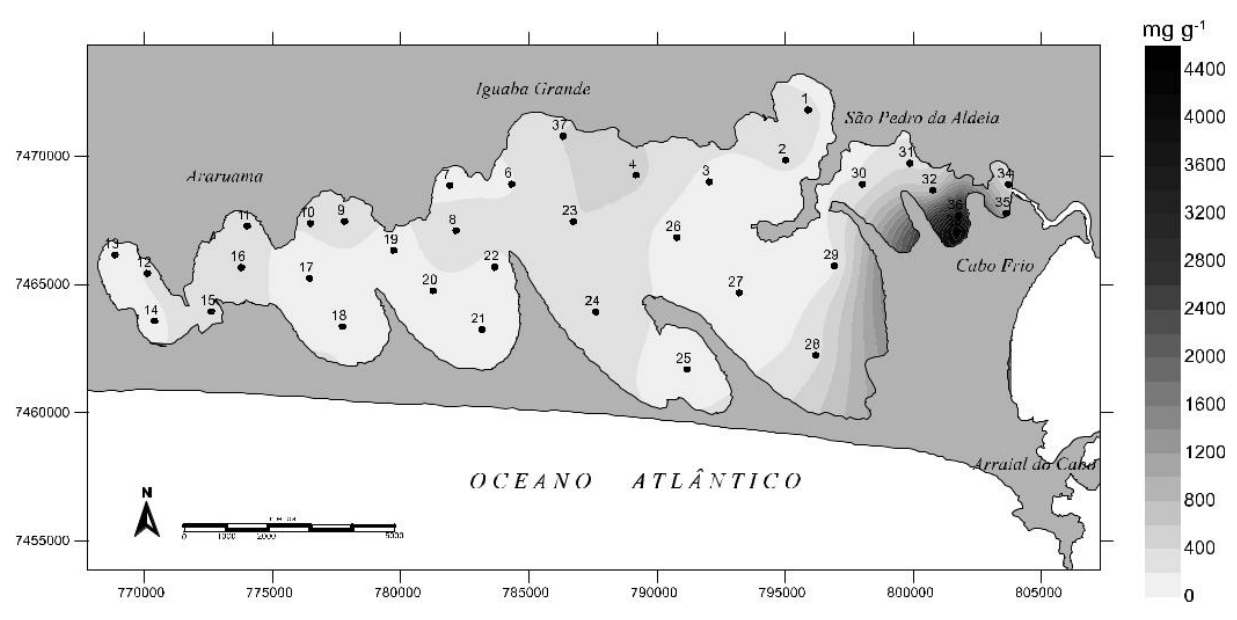

Figura 11

Distribuição do fósforo total nos sedimentos da Laguna de Araruama.

Estas concentrações são bastante elevadas na água intersticial, demonstrando que não há mais intenso consumo de nutrientes que, como mencionado na introdução, seria responsável pela produtividade primária do sedimento. A ausência de produtividade primária no sedimento, devido à diminuição da luminosidade (dada pela excessiva produção primária pelágica) vem promovendo $\mathrm{o}$ enriquecimento das concentrações deste elemento que era considerado limitante nos sedimentos. Pelo menos, no extremo Leste da 
laguna, ele não é mais o elemento limitante. Observa-se, ainda, a importância da fração dissolvida de fósforo em relação à concentração total de fósforo, indicando que não existe mais nenhum processo de precipitação desse nutriente neste sedimento.
A distribuição do carbono orgânico total (Figura 12) corrobora o processo apresentado que indica a existência de duas principais fontes de nutrientes para a laguna, uma associada à cidade de Iguaba Grande e outra associada aos aportes do Centro de Cabo Frio.

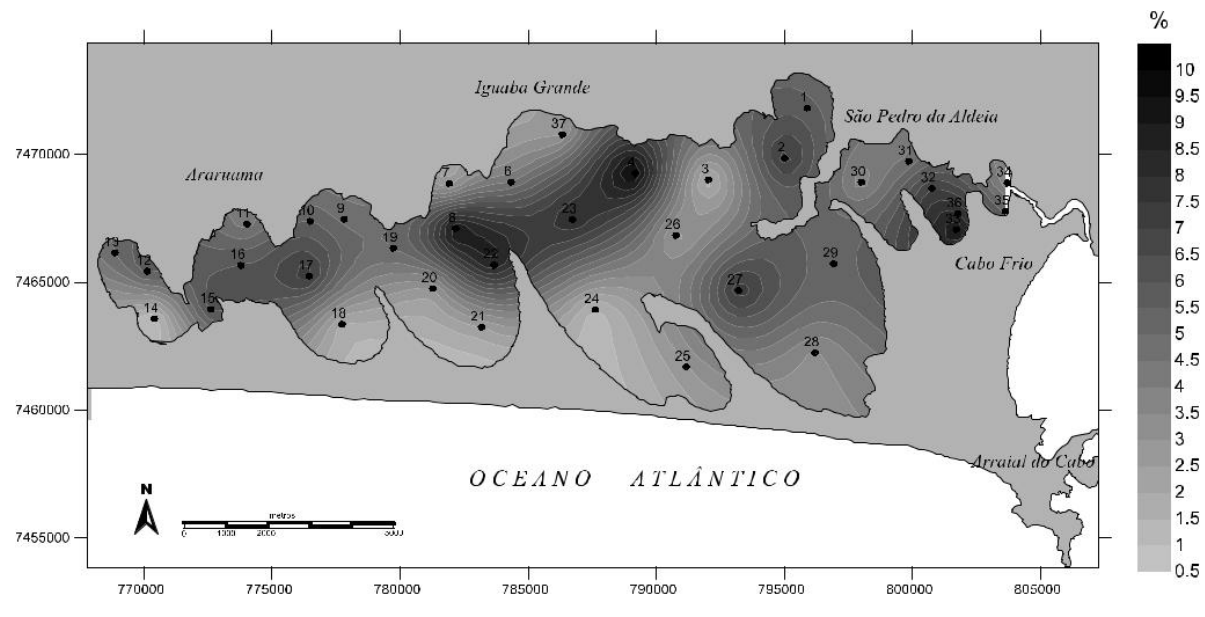

Figura 12

Distribuição do carbono total nos sedimentos da Laguna de Araruama.

Aparentemente, estes dois processos parecem ser os principais na contaminação da Laguna de Araruama. É notável o fato de não haver tanta contaminação dos sedimentos nas regiões mais a Oeste, onde a circulação é mais restrita, o sedimento é mais fino e a ocupação das margens é ainda mais intensa (caso de Araruama e do rio Mataruna). Evidentemente, trata-se unicamente do sedimento e não há, necessariamente, implicações em termos da contaminação da coluna d'água.

Foram avaliados os perfis de salinidade e temperatura em uma seleção de estações, de onde foram coletados, também, os sedimentos. Os resultados indicam a presença de uma marcada termoclina de um a dois graus Célcius que pode ser atribuída ao aquecimento solar das águas de superfície. Não obstante, os perfis de salinidade não mostram nenhum tipo de estratificação por densidade. Não observou-se nenhum processo de intensa evaporação na superfície, promovendo uma estratificação de águas mais salinas. As diferenças entre as salinidades na superfície e no fundo são muito pequenas (da ordem de décimos). Existe uma variação horizontal na salinidade, onde as estações localizadas no Canal de Itajuru apresentam valores abaixo de 50. Da mesma forma, as estações mais a Oeste, que recebem mais importantes aportes de água doce, também apresentam concentrações abaixo de 50. Todo o resto da laguna apresenta concentrações pouco acima de 51 de salinidade, um valor que corrobora os outros estudos feitos na região. Em outras palavras, não observou-se uma efetiva dessalinização do corpo d'água. Estes parâmetros são importantes, pois podem ter forte influência nos processos de difusão e afetar diretamente as concentrações de nutrientes na água intersticial.

Ao observar os mapas da análise granulométrica, é interessante verificar que a granulometria não é muito bem distribuída ao longo da laguna. Poucos sedimentos cascalhosos são observados na porção norte da laguna, nas proximidades de São Pedro da Aldeia (Figura 13). A verificação visual destes sedimentos indica a presença de grande quantidade de conchas, e não de cascalho propriamente dito. Pode-se observar uma predominânica de sedimentos arenosos (Figura 14). Na porção central e oeste, observam-se sedimentos finos (Figura 15), mostrando que estas áreas têm baixa hidrodinâmica, potencial redox muito redutor e, por esta razão, são áreas de acumulação de material autóctone e detrítico. 


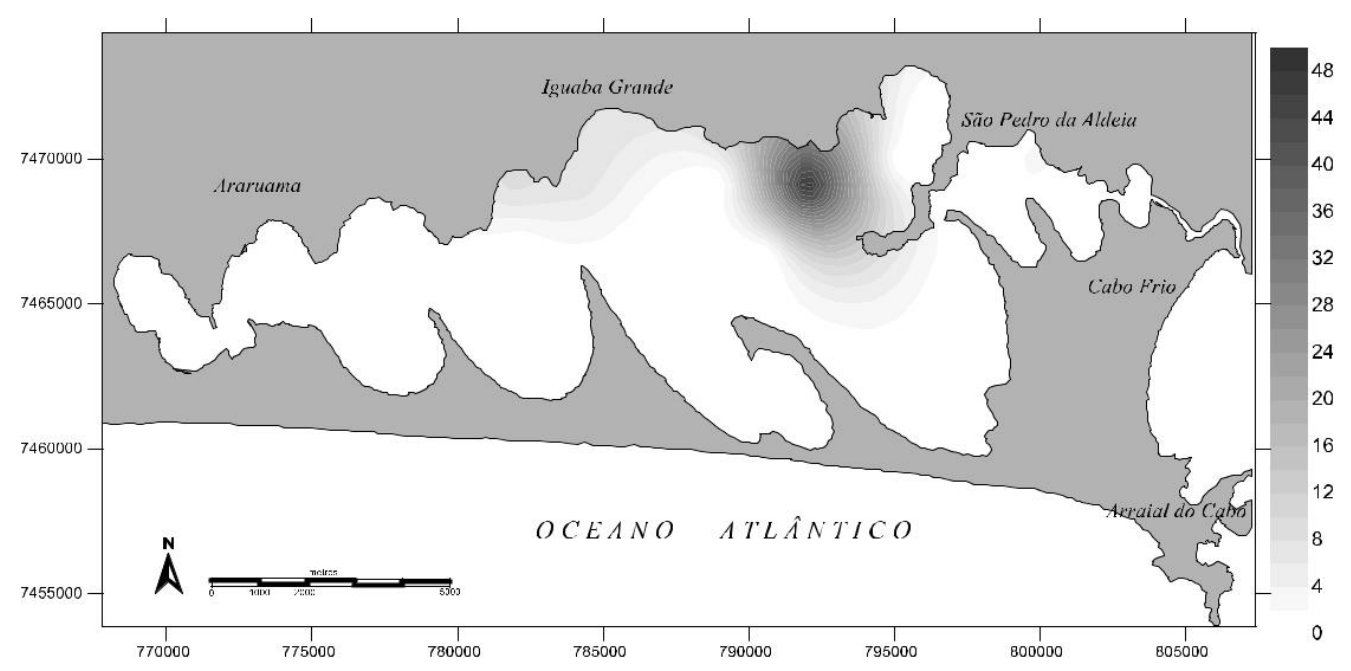

Figura 13

Distribuição da granulometria do tipo cascalho nos sedimentos da Laguna de Araruama. Dados em \%.

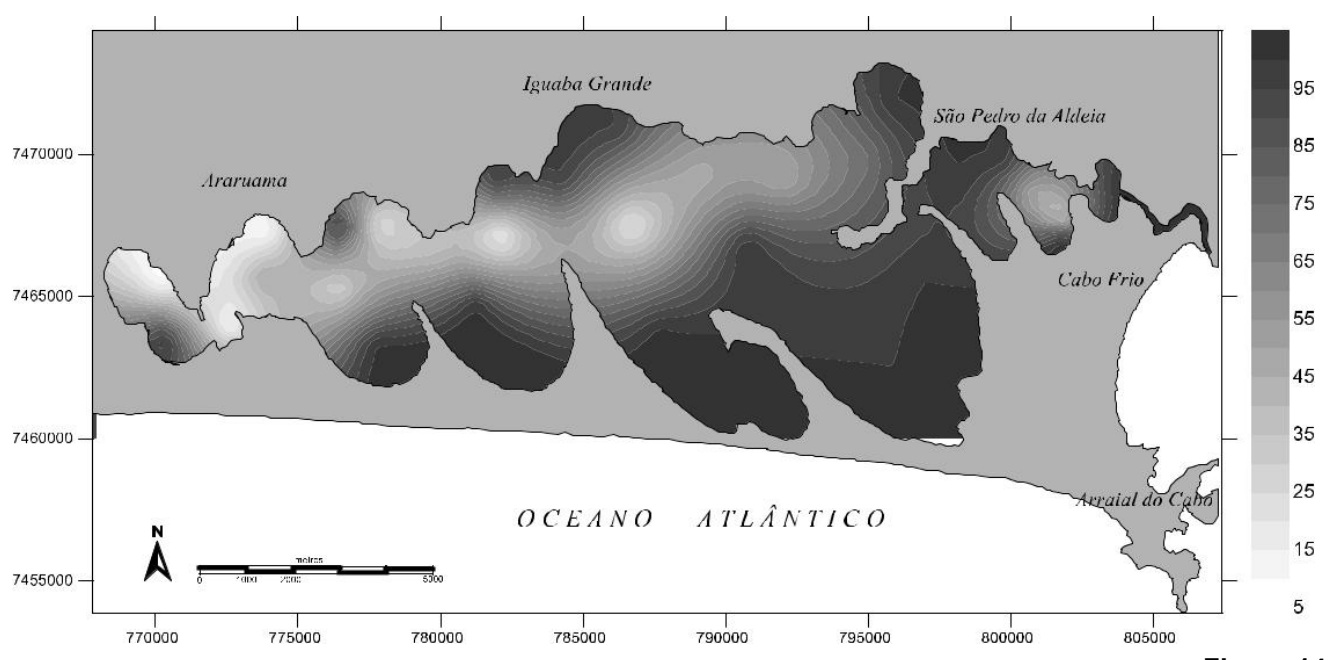

Figura 14

Distribuição da granulometria do tipo areia nos sedimentos da Laguna de Araruama. Dados em \%.

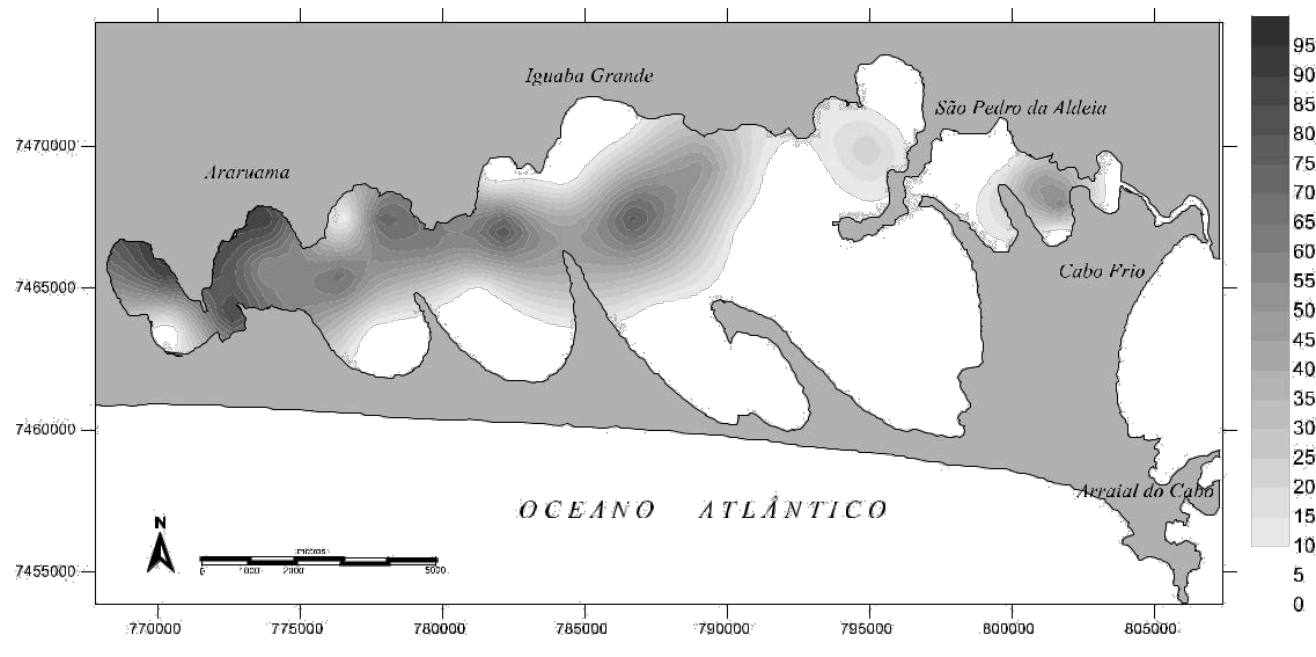

Figura 15

Distribuição da granulometria do tipo lama nos sedimentos da Laguna de Araruama. Dados em \%. 


\section{CONCLUSÕES}

A laguna está em um grau elevado de poluição em pontos específicos, devido ao aporte de nutrientes oriundos dos efluentes dos rios e do lançamento de esgotos, não devidamente tratatos, na mesma. Com a desobstrução do Canal de Itajuru, esperava-se que a entrada da água do mar, pobre em fósforo, promovesse a diluição das águas, diminuindo a concentração de fósforo no local, porém essa concentração permanece alta. Observa-se, também, uma elevada concentração de nitrogênio inorgânico total,

\section{AGRADECIMENTOS}

Os autores agradecem ao Conselho Nacional de Desenvolvimento Científico e Tecnológico (CNPq) pela bolsa de pesquisa do Projeto Universal e também à FAPERJ pela

\section{REFERÊNCIAS}

Alves A.R. 2003. Modelagem numérica como ferramenta de gestão ambiental. Aplicação ao sistema lagunar de Saquarema, RJ Dissertação de Mestrado, Programa de Pós-Graduação em Ciência Ambiental, Universidade Federal Fluminense, $97 \mathrm{p}$.

Alves A.R., Wasserman J.C., Bérenger R. \& Achete F.M. 2005. Modelagem Numérica do Transporte Litorâneo na Lagoa de Araruama. In $\mathrm{X}$ Congresso da Associação Brasileira de Estudos Quaternários, p.791-796.

Bidegain P.S. \&Bizerril C.R. 2002. Lagoa de Araruama - Perfil ambiental do maior ecossistema lagunar hipersalino do mundo Secretaria de Estado de Meio Ambiente e Desenvolvimento Sustentável do Estado do Rio de Janeiro, 1: 1-160.

Blott S.J. \&Pye K. 2001. Gradistat: A Grain Size Distribution and Statistics Package for the Analysis of Unconsolidated Sediments. Earth Surface Processes and Landforms, 26: $1237-$ 1248.

Gava G.L. 2008. Modelagem hidrodinâmica da Laguna de Araruama com vistas à previsão de impactos da abertura de um canal de ligação com o mar. PENO - COPPE, UFRJ, Rio de Janeiro.: 165.

Gerritse R. 2000. Nutrientes, Water quality and Algal Blooms in the Canning Catchment National Heritage Trust, 2: 1-22.

Grasshoff K., Ehrhardt M. \& Kremling K. 1983. Methods of Seawater Analysis Verlag Chemie, Weinheim, 2:419.

Kjerfve B., Schettini C., Knoppers B., Lessa G. \& Ferreira H. 1996. Hydrology and salt balance in a large, hypersaline coastal lagoon: Lagoa de principalmente através do amônio, indicando significativo aporte de esgotos domésticos na laguna.

A Laguna de Araruama necessita de uma intervenção urgente, devido ao seu contínuo avanço de degradação ambiental. As ações por parte da consciência da população e da mobilidade do governo estadual podem ser ainda mais decisivas em relação a soluções projetadas em pesquisas científicas. Ambas, porém, necessitam de planejamento, execução de tarefas e controle da gestão ambiental.

bolsa de iniciação científica (processo $\mathrm{n}^{\circ}$ 202775) concedida à aluna Kaylanne Montenegro para conclusão da pesquisa.

Araruama, Brazil. Estuar. Coast. Shelf Sci., 42: 701-725.

Kjerfve B.E. \&Knoppers B.A. 1999. Physical characteristics of lagoons of the East Fluminense Coast, state of Rio de Janeiro, Brazil. Série Geoquímica Ambiental, 6: 161169.

Knoppers B.A. \&Bidone E.D. 1999. Environmental geochemistry of coastal lagoon systems of Rio de Janeiro.Geoquímica Ambiental. Niterói: Programa de Geoquímica - UFF, 6: 210-220.

Lopez P. 2003. Effect of changes in water salinity on ammonium, calcium, dissolved inorganic carbon and influence on water/sediment dynamics. Estuarine Coastal and Shelf Science, 56: 943-956.

Oliveira P.S.D. 2010. The dynamics of nutrients in water and its influence on the process of eutrophication of the mangrove channel Espaço de diálogos e práticas - Associação dos Geógrafos Brasileiros, 16: 1-11.

Silva V.E.C., Franco D., Fonseca A.L., Fontes M.L. \& Donnangelo A.R. 2017. Space time evolution of the trophic state of a subtropical lagoon: Lagoa da Conceição, Florianópolis Island of Santa Catarina, Brazil. Scielo Analytics Revista Brasileira de Recursos Hídricos, 22: 117.

Wasserman, Alves A.R., Bérenger R. \& Achete F.M. 2000. Modelagem numérica do transporte litorâneo da Lagoa de Araruama - RJ LAGEMAR - UFF: 1-6.

Wasserman J.C. 2006. Avaliação ambiental da laguna de Araruama, para subsidiar um 
programa de recuperação e gestão. Relatório de Pesquisa. In: Avaliação ambiental em Araruama.

Zhang J. \&Fisher C.J. 2005. A simplified resorcinol method for direct spectrophotometric determination of nitrate in seawater. Marine Chemistry, 99: 220-226.

Zoumis T. \&Schmidt A. 2001. Contaminants in sediments: remobilization and demobilisation. Science of the Total Environment, 266: 195202. 